\title{
Angiotensin II Stimulates Spinally Projecting Paraventricular Neurons through Presynaptic Disinhibition
}

\author{
De-Pei Li, ${ }^{1}$ Shao-Rui Chen, ${ }^{1}$ and Hui-Lin Pan ${ }^{1,2}$ \\ Departments of ${ }^{1}$ Anesthesiology and ${ }^{2}$ Neuroscience and Anatomy, The Pennsylvania State University College of Medicine, The Milton S. Hershey Medical \\ Center, Hershey, Pennsylvania 17033-0850
}

\begin{abstract}
Paraventricular nucleus (PVN) neurons that project to the spinal cord are important in the control of sympathetic outflow. Angiotensin II (Ang II) can stimulate PVN neurons, but its cellular mechanisms are not clear. In this study, we determined the effect of Ang II on the excitatory and inhibitory synaptic inputs to spinally projecting PVN neurons. Whole-cell patch-clamp recordings were performed on PVN neurons labeled by a retrograde fluorescence tracer injected into the thoracic spinal cord of rats. Immunocytochemistry labeling revealed that the immunoreactivity of angiotensin type $1\left(\mathrm{AT}_{1}\right)$ receptors was colocalized with a presynaptic marker, synaptophysin, in the PVN. Application of 0.1-5 $\mu \mathrm{M}$ Ang II significantly decreased the amplitude of evoked GABAergic IPSCs in a concentration-dependent manner. Also, Ang II decreased the frequency of miniature IPSCs from $2.56 \pm 0.45$ to $1.05 \pm 0.20 \mathrm{~Hz}(p<0.05 ; n=12)$, without affecting the amplitude and the decay time constant. The effect of Ang II on miniature IPSCs was blocked by losartan but not PD123319. However, Ang II had no effect on the evoked glutamatergic EPSCs and did not alter the frequency and amplitude of miniature EPSCs at concentrations that attenuated IPSCs. Furthermore, Ang II increased the firing rate of PVN neurons from $3.75 \pm 0.36$ to $7.89 \pm 0.85 \mathrm{~Hz}(p<0.05$; $n=9$ ), and such an effect was abolished by losartan. In addition, Ang II failed to excite PVN neurons in the presence of bicuculline. Thus, this study provides substantial new evidence that Ang II excites spinally projecting PVN neurons by attenuation of GABAergic synaptic inputs through activation of presynaptic $\mathrm{AT}_{1}$ receptors.
\end{abstract}

Key words: renin-angiotensin system; synaptic transmission; GABA; angiotensin receptors; sympathetic nervous system; hypothalamus

\section{Introduction}

Neurons in the paraventricular nucleus (PVN) of the hypothalamus are critically involved in the regulation of neuroendocrine, cardiovascular, and other physiological functions (Swanson and Sawchenko, 1983). The PVN is a heterogenous structure that contains interneurons and output neurons projecting to the brainstem autonomic center and sympathetic preganglionic neurons located in the intermediolateral cell column of the spinal cord, among others (Ranson et al., 1998; Pyner and Coote, 2000; Hardy, 2001). Stimulation of PVN neurons can directly and indirectly influence the sympathetic outflow and blood pressure, especially during stress and certain types of hypertension (Ranson et al., 1998; de Wardener, 2001; Allen, 2002; Miyakubo et al., 2002).

Angiotensin II (Ang II), a potent effector of the reninangiotensin system, plays an important role in the control of the balance of hydromineral and fluid volume, as well as sympathetic efferent activity (Swanson and Sawchenko, 1983). Intracerebroventricular administration of Ang II causes an increase in blood pressure, excitation of the sympathetic nervous system, and release of vasopressin (Hogarty et al., 1992; Lon et al., 1996). Ang II acts as both a circulating signal through receptors in the circum-

Received Nov. 4, 2002; revised March 31, 2003; accepted April 2, 2003.

This study was supported by National Institutes of Health (NIH) Grants HL60026 and HL04199. D.P.L. was supported by an American Heart Association Postdoctoral Fellowship (Pennsylvania-Delaware affiliate). H.L.P. was a recipient of an NIH Independent Scientist Award during this study. We thank Roland Myers for technical support, Pamela Myers for secretarial assistance, and Merck for providing losartan.

Correspondence should be addressed to Dr. Hui-Lin Pan, Department of Anesthesiology, H187, The Pennsylvania State University College of Medicine, 500 University Drive, Hershey, PA 17033-0850. E-mail: hpan@psu.edu. Copyright $\odot 2003$ Society for Neuroscience $\quad$ 0270-6474/03/235041-09\$15.00/0 ventricular organs and as a neurotransmitter in several areas of the hypothalamus and medulla known to be involved in autonomic and endocrine regulation. In this regard, circulating Ang II can influence the excitability of PVN neurons through synaptic connections with circumventricular organs (Bains and Ferguson, 1995; Miyakubo et al., 2002; Zhang et al., 2002). Furthermore, all of the components of the renin-angiotensin system, such as angiotensinogen, angiotensin-converting enzyme, and angiotensin receptors, exist in the PVN (Ferguson and Washburn, 1998). For instance, it has been shown that angiotensin type $1\left(\mathrm{AT}_{1}\right)$ receptors and their mRNA are densely distributed in the PVN (Gehlert et al., 1991). The PVN neurons projecting to the spinal cord receive angiotensinergic afferent inputs within the PVN and from surrounding regions such as the subfornical organ (Lind et al., 1985; Li and Ferguson, 1993; Bains and Ferguson, 1995). The sympatho-excitatory responses induced by stimulation of cardiac receptors or hyperosmolality are blocked by a specific $\mathrm{AT}_{1}$ receptor antagonist, losartan, injected into the PVN (Chen and Toney, 2001; Zhu et al., 2002). However, the cellular mechanisms underlying the action of Ang II on spinally projecting PVN neurons remain poorly understood.

Both GABA and glutamate are major neurotransmitters in the PVN (Hermes et al., 1996; Cui et al., 2001), and the vast majority of the local synaptic inputs to PVN neurons are GABAergic (Tasker and Dudek, 1993; Boudaba et al., 1996). Consistent with the previous findings, microinjection of a $\mathrm{GABA}_{\mathrm{A}}$ receptor antagonist, bicuculline, into the PVN in conscious rats profoundly increases blood pressure and heart rate (Martin and Haywood, 1993; Schlenker et al., 2001). However, the effect of Ang II on GABAergic and glutamatergic synaptic inputs to spinally project- 
ing PVN neurons has not been investigated specifically. Therefore, in this study, we combined the retrograde-labeling and in vitro whole-cell recording techniques to determine the effect of Ang II on the inhibitory GABAergic and excitatory glutamatergic synaptic inputs to spinally projecting PVN neurons. We also studied the influence of the presynaptic effect of Ang II on the excitability of spinally projecting PVN neurons.

\section{Materials and Methods}

Retrograde labeling of spinally projecting PVN neurons. Sprague Dawley rats (3-5 weeks of age; Harlan Sprague Dawley, Indianapolis, IN) of either sex were used for this study. The surgical preparations and experimental protocols were approved by the Animal Care and Use Committee (The Pennsylvania State University College of Medicine, Hershey, PA) and conformed to the National Institutes of Health guidelines on the ethical use of animals. All efforts were made to minimize both the suffering and number of animals used. The spinal cord at the T1-T4 level was exposed through dorsal laminectomy under halothane anesthesia. A rhodamine-labeled fluorescent microsphere suspension (FluoSpheres, $0.04 \mu \mathrm{m}$; Molecular Probes, Eugene, OR) was pressure ejected (Picospritzer II; General Valve, Fairfield, NJ) bilaterally into the region of the intermediolateral cell column of the spinal cord in two or three separate $50 \mathrm{nl}$ injections using a glass micropipette (tip diameter, $20-30 \mu \mathrm{m}$ ). The pipette was positioned with a micromanipulator at $\sim 500 \mu \mathrm{m}$ below the dorsolateral sulcus, and the tracer injection was monitored through a surgical microscope (Li et al., 2002a). The muscles were sutured, and the wound was closed after injection. Animals were returned to their cages for 3-10 d, which is sufficient time to permit retrograde tracer being transported to the PVN. To assess the health status of the animals, the rats were inspected daily for motor activity, signs of infection, and food and water intake.

Slice preparations. Three to $10 \mathrm{~d}$ after fluorescent tracer injection, the rats were rapidly decapitated under halothane anesthesia. The brain was quickly removed and placed in ice-cold artificial CSF (aCSF) saturated with $95 \% \mathrm{O}_{2}$ and $5 \% \mathrm{CO}_{2}$. A tissue block containing the hypothalamus was cut from the brain and glued onto the stage of the vibratome (Technical Product International, St. Louis, MO) as described previously ( $\mathrm{Li}$ and Pan, 2001; Li et al., 2002a). Coronal slices (thickness, $300 \mu \mathrm{m}$ ) containing the PVN were cut from the tissue block in the ice-cold aCSF. The slices were preincubated in aCSF, which was continuously gassed with $95 \% \mathrm{O}_{2}$ and $5 \% \mathrm{CO}_{2}$ at $34^{\circ} \mathrm{C}$ for $1 \mathrm{hr}$ until they were transferred to the recording chamber. The perfusion solution contained the following (in $\mathrm{mm}$ ): $124 \mathrm{NaCl}, 3 \mathrm{KCl}, 1.3 \mathrm{MgSO}_{4}, 2.4 \mathrm{CaCl}_{2}, 1.4 \mathrm{NaH}_{2} \mathrm{PO}_{4}, 10$ glucose, and $26 \mathrm{NaHCO}_{3}$.

Recordings of postsynaptic currents and firing activity of labeled PVN neurons. Recordings of postsynaptic currents were performed in a radio frequency-shielded room using the whole-cell voltage-clamp technique as described previously (Li and Pan, 2001; Li et al., 2002a; Pan et al., 2002). The recording pipettes were triple pulled using borosilicate capillaries (outer diameter, $1.2 \mathrm{~mm}$; inner diameter, $0.86 \mathrm{~mm}$; World Precision Instruments, Sarasota, FL). The resistance of the pipette was 4-8 $\mathrm{M} \Omega$ when filled with the internal solution containing the following: 130 mM potassium gluconate, $1 \mathrm{~mm} \mathrm{MgCl}_{2}, 10 \mathrm{~mm}$ HEPES, 10 mм EGTA, 1 $\mathrm{mm} \mathrm{CaCl}_{2}$, and $4 \mathrm{~mm} \mathrm{ATP-Mg}$, adjusted to $\mathrm{pH} 7.25$, with $1 \mathrm{M} \mathrm{KOH}$ (290-320 mOsm). The slice was placed in a glass-bottomed chamber (Warner Instruments, Hamden, CT) and fixed with a grid of parallel nylon threads supported by a U-shaped stainless steel weight. The slice was perfused at $3 \mathrm{ml} / \mathrm{min}$ at $34^{\circ} \mathrm{C}$ and maintained by an in-line solution heater and temperature controller (model TC-324; Warner Instruments). It took $\sim 1 \mathrm{~min}$ to completely exchange the solution inside the recording chamber at the perfusion rate of $3 \mathrm{ml} / \mathrm{min}$. Whole-cell recordings from labeled PVN neurons were performed under visual control using a combination of epifluoresence illumination and differential interference contrast (DIC) optics on an upright microscope (BX50 WI; Olympus Optical, Tokyo, Japan). The fluorescence-labeled neurons located in the medial one-third of the PVN area between the third ventricle and the fornix were selected for recording ( $\mathrm{Li}$ et al., 2002a). The labeled neurons were briefly identified with the aid of epifluorescence illumina- tion. A tight gigaohm seal was subsequently obtained in the labeled neuron viewed with DIC optics. Recordings of postsynaptic currents began 5 min after the whole-cell access was established and the current reached a steady state. Signals were processed with an Axopatch 200B amplifier (Axon Instruments, Foster City, CA). A liquid junction potential of - 15 $\mathrm{mV}$ (for the potassium gluconate pipette solution) was corrected during off-line analysis. Signals were filtered at $1-2 \mathrm{kHz}$, digitized at $10 \mathrm{kHz}$ using Digidata 1320 (Axon Instruments), and saved to the hard drive of a computer. The miniature IPSCs (mIPSCs) were recorded in the presence of $1 \mu \mathrm{M}$ tetrodotoxin (TTX) and $20 \mu \mathrm{M}$ 6-cyano-7-nitroquinoxaline-2,3-dione (CNQX) (a glutamate non-NMDA receptor antagonist) at a holding potential of $0 \mathrm{mV}$, and the miniature EPSCs (mEPSCs) were recorded in the presence of $1 \mu \mathrm{M}$ TTX and $20 \mu \mathrm{M}$ bicuculline at a holding potential of -70 $\mathrm{mV}$ (Li and Pan, 2001; Li et al., 2002a; Pan et al., 2002). In some experiments, $1 \mathrm{~mm}$ guanosine $5^{\prime}$-O-(2-thiodiphosphate) (GDP- $\beta$-s) (a G-protein inhibitor) was added into the recording pipette solution to block the possible postsynaptic response mediated by G-protein activation coupled to angiotensin receptors. The effective concentration of GDP- $\beta$-s to block the effect of Ang II has been shown in previous studies (Ohya and Sperelakis, 1991; Oz and Renaud, 2002).

To study the evoked IPSCs (eIPSCs) and evoked EPSCs (eEPSCs) in labeled PVN neurons, synaptic currents were evoked by electrical stimulation $(0.1 \mathrm{msec} ; 0.3-0.8 \mathrm{~mA} ; 0.1 \mathrm{~Hz})$ through a bipolar tungsten electrode connected to a stimulator (Grass Instruments, West Warwick, RI). The tip of the stimulating electrode was placed $200-800 \mu \mathrm{m}$ away from the recorded neuron (Pan et al., 2002). A sodium channel blocker, $N$-ethyl bromide quaternary salt (QX-314) (10 mM), and GDP- $\beta$-s (1 mM) were included in the pipette solution to block the $\mathrm{Na}^{+}$current and possible postsynaptic effect in these voltage-clamp experiments. On the basis of the optimal reversal potentials determined for CNQX-sensitive EPSCs and bicuculline-sensitive IPSCs (see Results), the eEPSCs and eIPSCs were recorded at a holding potential of -70 and $0 \mathrm{mV}$, respectively.

The spontaneous firing activity of labeled PVN neurons was recorded using the whole-cell current-clamp technique (Li et al., 2002a). The recording procedures were similar to those used for postsynaptic current recordings as described above except that TTX and QX-314 were not used. Recordings of the firing activity of labeled PVN neurons began $\sim 5$ min after the whole-cell access was established and the firing activity reached a steady state. Signals were processed, recorded, and analyzed as described above.

To ensure that the recorded neurons were located in the PVN, biocytin $(0.2 \%)$ was added into the internal pipette solution. After recordings, slices were fixed in $4 \%$ paraformaldehyde in $0.1 \mathrm{M}$ phosphate buffer, $\mathrm{pH}$ 7.4, for 7-10 d. To visualize PVN neurons labeled by biocytin, the sections were rinsed for $20 \mathrm{~min}$ in Tris-buffered saline and incubated with streptavidin-conjugated Alexa Fluor-594 (5 $\mu \mathrm{g} / \mathrm{ml}$; Molecular Probes) for $1.5 \mathrm{hr}$ at room temperature. The sections were then rinsed in Trisbuffered saline for $40 \mathrm{~min}$, mounted on slides, dried, and coverslipped ( $\mathrm{Li}$ et al., 2002a). The sections were viewed using a fluorescence microscope, and the recovered neurons were photographed.

Ang II, PD123319, CNQX, bicuculline, and GDP- $\beta$-s were obtained from Sigma (St. Louis, MO). Losartan was a gift from Merck (Rahway, NJ). TTX and QX-314 were purchased from Alomone Labs (Jerusalem, Israel). All of the drugs were prepared immediately before the experiments and applied to the slice chamber using syringe pumps.

Immunofluorescence double labeling of $A T_{1}$ receptors and synaptophysin in the PVN. To determine whether $\mathrm{AT}_{1}$ receptors are located presynaptically in the PVN, sections from the hypothalamus were immunolabeled for colocalization of the $\mathrm{AT}_{1}$ receptor and synaptophysin, a specific marker for presynaptic terminals (Hiscock et al., 2000) in three rats. Under deep anesthesia with sodium pentobarbital (60 mg/kg, i.p.), rats were intracardially perfused with $200 \mathrm{ml}$ of ice-cold normal saline containing $1000 \mathrm{U}$ of heparin, followed by $500 \mathrm{ml}$ of $4 \%$ paraformaldehyde and $250 \mathrm{ml}$ of $10 \%$ sucrose in $0.1 \mathrm{M} \mathrm{PBS}, \mathrm{pH}$ 7.4. The brain was removed quickly and postfixed for $2 \mathrm{hr}$ in the same fixative solution and cryoprotected in $30 \%$ sucrose in PBS for $48 \mathrm{hr}$ at $4^{\circ} \mathrm{C}$. Sections were cut to $35 \mu \mathrm{m}$ in thickness and collected free floating in $0.1 \mathrm{~m}$ PBS. The sections were rinsed in $0.1 \mathrm{M}$ PBS and then incubated with the primary antibody mix- 
ture diluted in PBS containing 2\% normal goat serum, 0.3\% Triton $\mathrm{X}-100$, and $0.05 \%$ Tween 20 for $2 \mathrm{hr}$ at room temperature and $48 \mathrm{hr}$ at $4^{\circ} \mathrm{C}$. The primary antibodies used were mouse anti-synaptophysin monoclonal IgM antibody (dilution, 1:100; Chemicon, Temecula, CA) and rabbit anti-AT 1 polyclonal IgG antibody (dilution, 1:50; Santa Cruz Biotechnology, Santa Cruz, CA). Sections were then rinsed in PBS and incubated with the secondary antibody mixture overnight at $4^{\circ} \mathrm{C}$. The secondary antibodies were biotin-SP-conjugated goat anti-mouse IgM (dilution, 1:200; Jackson ImmunoResearch, West Grove, PA) and Alexa Fluor- 488 conjugate of goat anti-rabbit IgG (dilution, $5 \mu \mathrm{g} / \mathrm{ml}$; Molecular Probes). Subsequently, the sections were rinsed and incubated with streptavidin, conjugated with Alexa Fluor-594 (dilution, $5 \mu \mathrm{g} / \mathrm{ml}$; Molecular Probes) for $1.5 \mathrm{hr}$ at room temperature. Finally, the sections were rinsed in PBS for 40 min, mounted on slides, dried, and coverslipped. The sections were then viewed using a confocal microscope (Zeiss, Oberkochen, Germany), and the areas of interest were photographed. Confocal laser scanning microscopy was used for accurate colocalization of fluorescent markers because the thin $(\sim 1 \mu \mathrm{m})$ optical sectioning generated by the confocal microscope eliminates the confounding effect of out-of-focus fluorescence. Digital images were adjusted for brightness and contrast using Photoshop 5.0 and digitally merged. In the highermagnification images, the colocalization was indicated by the color change (yellow) and represents colocalization (Li et al., 2002a; Pan et al., 2002).

To assess the spatial relationship of recorded neurons with the $\mathrm{AT}_{1}$ receptor in the $\mathrm{PVN}$, we performed immunolabeling of $\mathrm{AT}_{1}$ receptors on 22 biocytin-labeled cells recovered from the slice recording. First, the sections were rinsed and blocked in $4 \%$ normal goat serum in PBS, followed by incubation with the mouse anti-synaptophysin monoclonal IgM antibody (Chemicon) for $2 \mathrm{hr}$ at room temperature and then overnight at $4^{\circ} \mathrm{C}$. Second, sections were rinsed and incubated with the biotinSP-conjugated goat anti-mouse IgM (Jackson ImmunoResearch). Subsequently, the sections were rinsed and incubated with streptavidin conjugated with Alexa Fluor-488 (Molecular Probes) for $1.5 \mathrm{hr}$ at room temperature. To identify biocytin-labeled cells, the sections were rinsed and incubated with Alexa Fluor-594 conjugated to streptavidin for $1.5 \mathrm{hr}$ at room temperature. All of the sections were viewed with a Zeiss confocal microscope.

Data analysis. Data are presented as means \pm SEM. To determine the amplitude of the eIPSCs and eEPSCs, at least 15 consecutive eIPSCs or eEPSCs were averaged and measured using pClamp 8.0 analysis software (Axon Instruments). The mIPSCs, mEPSCs, and the firing activity were analyzed off-line with a peak detection program (MiniAnalysis; Synaptosoft, Leonia, NJ). Detection of events was accomplished by setting a threshold above the noise level. The cumulative probability of the amplitude and interevent interval of mEPSCs and/or mIPSCs was compared using the Komogorov-Smirnov test, which estimates the probability that two cumulative distributions are similar. At least 100 mIPSCs and mEPSCs were used in each analysis. The effects of drugs on the peak amplitude of eIPSCs and eEPSCs, and the amplitude and frequency of mIPSCs and mEPSCs, were determined by the nonparametric Wilcoxon signed rank test or nonparametric ANOVA (Kruskal-Wallis) with Dunn's post hoc test ( $p<0.05$ was considered to be statistically significant).

\section{Results}

Whole-cell patch-clamp recordings were performed on 97 PVN cells ( $n=38$ rats) labeled by FluoSpheres. After killing the rat, the spinal cord was taken out and viewed under a microscope equipped with fluorescence illumination to verify the injection and diffusion site of the tracer. The site was primarily located in and around the intermediolateral cell column of the spinal cord (data not shown). Figure 1 shows a FluoSphere-labeled PVN neuron identified initially with a rhodamine fluorescence filter (Fig. $1 A$ ) and subsequently recorded using DIC optics (Fig. $1 B$ ). The location of all recovered neurons labeled with biocytin was confirmed histologically in the PVN after staining (Fig. 1C). The labeled PVN neurons displayed a resting membrane potential ranging from -78.3 to $-58.4 \mathrm{mV}(-63.7 \pm 4.8 \mathrm{mV})$, an input
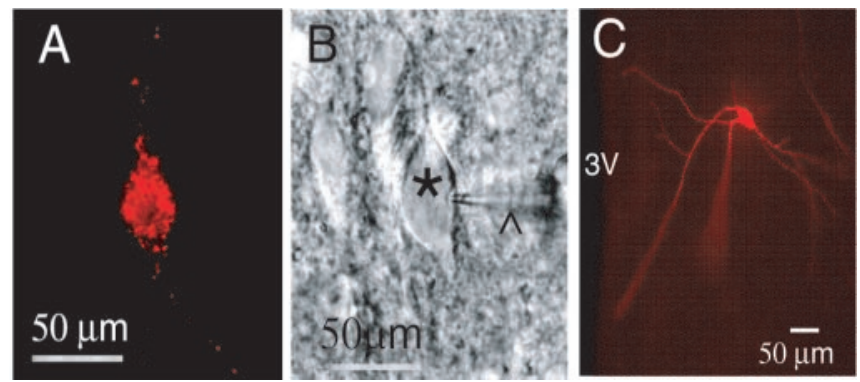

Figure 1. Identification of a retrogradely labeled spinally projecting PVN neuron. $A, A$ FluoSphere-labeled PVN neuron in the slice viewed with fluorescence illumination. $B$, Photomicrograph of the same neuron $\left(^{*}\right)$ shown in $A$ with an attached recording electrode $(\wedge)$ in the slice viewed with differential interference contrast optics. $C$, Photomicrograph showing the morphology of a recorded PVN neuron labeled with biocytin. 3V, Third ventricle. Scale bars, $50 \mu \mathrm{m}$.

resistance between 360 and $540 \mathrm{M} \Omega(432.7 \pm 32.7 \mathrm{M} \Omega)$, and an amplitude of action potentials larger than $60 \mathrm{mV}$.

\section{Effect of Ang II on evoked EPSCs and IPSCs of labeled PVN neurons}

Both eEPSCs and eIPSCs were evoked in 9 of 12 FluoSpherelabeled PVN neurons, and only IPSCs were evoked without detectable EPSCs in the remaining three cells. To evaluate the effect of Ang II on synaptic inputs to labeled PVN neurons, both IPSCs and EPSCs were evoked by electrical stimulation at a constant intensity $(n=9)$. All of the evoked postsynaptic currents were monosynaptic because neither conduction failure nor variance in latency occurred when the stimulation frequency was increased to $20 \mathrm{~Hz}$, consistent with the criteria used for identification of the monosynaptic input (Li et al., 2002b). The evoked synaptic currents were changed from inward to outward when the holding potential was increased from -80 to $0 \mathrm{mV}$ (Fig. $2 \mathrm{~A}$ ). To determine the relative contribution of eEPSCs (inward) and eIPSCs (outward) to the total synaptic current, the slice was treated with CNQX $(20 \mu \mathrm{M})$ to abolish the non-NMDA receptor-mediated EPSCs and bicuculline $(20 \mu \mathrm{M})$ to eliminate $\mathrm{GABA}_{\mathrm{A}}$ receptormediated IPSCs from the total synaptic current (Pan et al., 2002). According to the relationship between synaptic currents and holding potentials, the reversal potentials for eIPSCs and eEPSCs were -70 and $0 \mathrm{mV}$, respectively (Fig. $2 B$ ). Therefore, the eEPSCs were isolated at a holding potential of $-70 \mathrm{mV}$, whereas the eIPSCs were isolated at a holding potential of $0 \mathrm{mV}$. The amplitude of eIPSCs was two to three times larger than that of eEPSCs $(200.5 \pm 34.6$ vs $67.1 \pm 18.6 \mathrm{pA} ; n=6 ; p<0.05)$ (Fig. $2 C)$.

The effect of Ang II on eEPSCs and eIPSCs was further examined in nine separate labeled neurons with both eIPSCs and eEPSCs. Ang II $(0.5-5 \mu \mathrm{M})$ inhibited the peak amplitude of eIPSCs in a concentration-dependent manner (Fig. 3). The peak amplitude of eIPSCs was reduced by Ang II at a concentration of $0.5 \mu \mathrm{M}$, and the inhibition reached the maximum $(\sim 52.2 \%)$ at a concentration of $2 \mu \mathrm{M}$ (Fig. $3 A, C)$. However, Ang II had no effect on the amplitude of eEPSCs even at the highest concentration used (Fig. $3 B, C$ ).

Ang II had no significant effect on the holding current and input resistance in 12 labeled PVN neurons used for recording eIPSCs and eEPSCs. The holding current was $61.7 \pm 8.2$ and $62.4 \pm 8 \mathrm{pA}$ during control and application of $2 \mu \mathrm{M}$ Ang II when the cell was voltage clamped at $0 \mathrm{mV}$. When the cell was clamped at $-70 \mathrm{mV}$, the hold current was $-24.1 \pm 5.8$ and $-23.1 \pm 5.6$ pA before and during application of $2 \mu \mathrm{M}$ Ang II. The input resistance before and during perfusion of $2 \mu \mathrm{M}$ Ang II was 


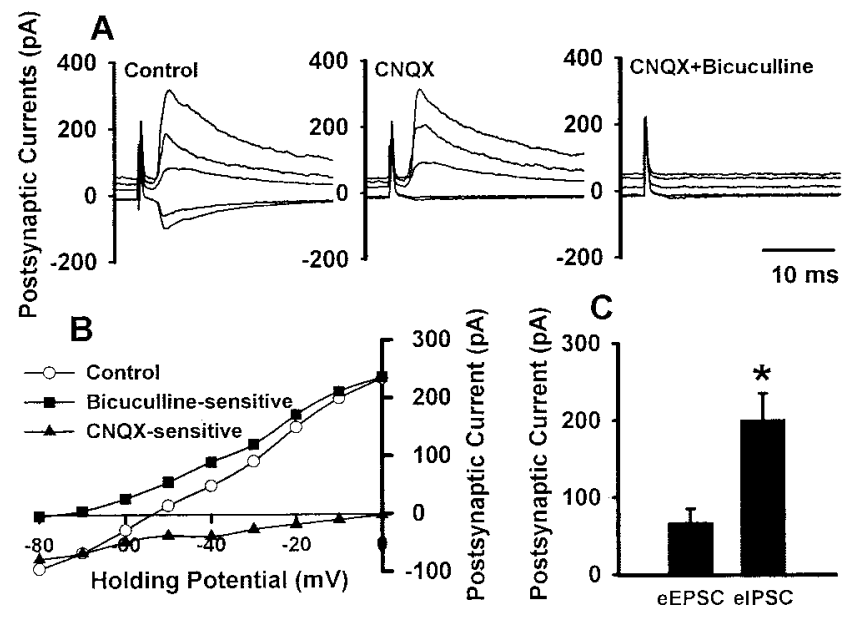

Figure 2. Evoked synaptic responses in labeled PVN neurons at different holding potentials. $A$, Focal stimulation-evoked synaptic currents under different holding potentials (from -80 to $0 \mathrm{mV}$ ). Synaptic responses were also recorded in the presence of $20 \mu \mathrm{m}$ CNQX or $20 \mu \mathrm{M}$ CNQX plus $20 \mu \mathrm{m}$ bicuculline. $B$, Peak $I-V$ relationships of the synaptic currents. The peak synaptic currents were plotted as a function of the holding potential. CNQX-sensitive currents $(\boldsymbol{\Delta})$ were obtained by subtracting peak synaptic currents measured in CNQX solution from those in control (๑). Bicuculline-sensitive currents ( $\square$ ) were obtained by subtracting synaptic currents measured in CNQX from those in CNQX plus bicuculline solution. C, Summary data showing the difference of peak synaptic currents measured at holding potentials of $-70 \mathrm{mV}$ (eEPSCs) and 0 $\mathrm{mV}$ (elPSCS). Data are presented as means \pm SEM $\left({ }^{*} p<0.05\right.$ compared with eEPSCs; $n=9$; Wilcoxon signed rank test).

$445.3 \pm 35.4$ and $438.5 \pm 32.3 \mathrm{M} \Omega$, respectively $(n=12 ; p<$ $0.05)$.

\section{Effect of Ang II on mIPSCs of labeled PVN neurons}

To determine the presynaptic effect of Ang II on GABAergic synaptic inputs to labeled PVN neurons, we examined the effect of Ang II on the spontaneous mIPSCs. The mIPSCs were recorded in the presence of $1 \mu \mathrm{M}$ TTX and $20 \mu \mathrm{M}$ CNQX. Application of 20 $\mu \mathrm{M}$ bicuculline completely abolished mIPSCs $(n=12)$ (Fig. $4 A)$. Ang II, in a concentration of $2 \mu \mathrm{M}$, significantly decreased the frequency of mIPSCs from $2.54 \pm 0.45$ to $1.25 \pm 0.20 \mathrm{~Hz}$ ( $p<$ 0.05 ) without affecting the amplitude and the decay time constant of mIPSCs in 12 neurons tested (Fig. 4). The cumulative probability analysis of mIPSCs before and during Ang II application revealed that the distribution pattern of the interevent interval of mIPSCs shifted to the right in response to Ang II, whereas the distribution pattern of the amplitude was not changed (Fig. $4 B, C)$. The decay phase of mIPSCs was best fitted by a doubleexponential function (Fig. $4 D$ ). Neither the fast $(5.69 \pm 0.45$ vs $6.02 \pm 0.35 \mathrm{msec})$ nor slow $(19.53 \pm 1.68$ vs $20.38 \pm 2.74 \mathrm{msec})$ component of the decay phase of mIPSCs during Ang II application was significantly different from those during the control. Repeat application of Ang II had a reproducible inhibitory effect on the frequency of mIPSCs in nine labeled PVN neurons (data not shown). To further determine the site of the effect of Ang II, GDP- $\beta$-s was included in the internal solutions to block the possible postsynaptic effect of Ang II in another group of nine cells. A similar effect of $2 \mu \mathrm{M}$ Ang II on the frequency (from $2.26 \pm 0.44$ to $1.12 \pm 0.25 \mathrm{~Hz} ; p<0.05$ ) of mIPSCs and the amplitude $(42.35 \pm 4.23$ to $43.69 \pm 4.26 \mathrm{pA} ; p>0.05)$ of mIPSCs was observed in these cells (Fig. $5 A, B$ ).

To determine the receptor subtype mediating the inhibitory effect of Ang II on mIPSCs, the specific antagonists for the $\mathrm{AT}_{1}$ (losartan) and $\mathrm{AT}_{2}$ (PD123319) receptors were used. The effective concentrations of these antagonists have been determined
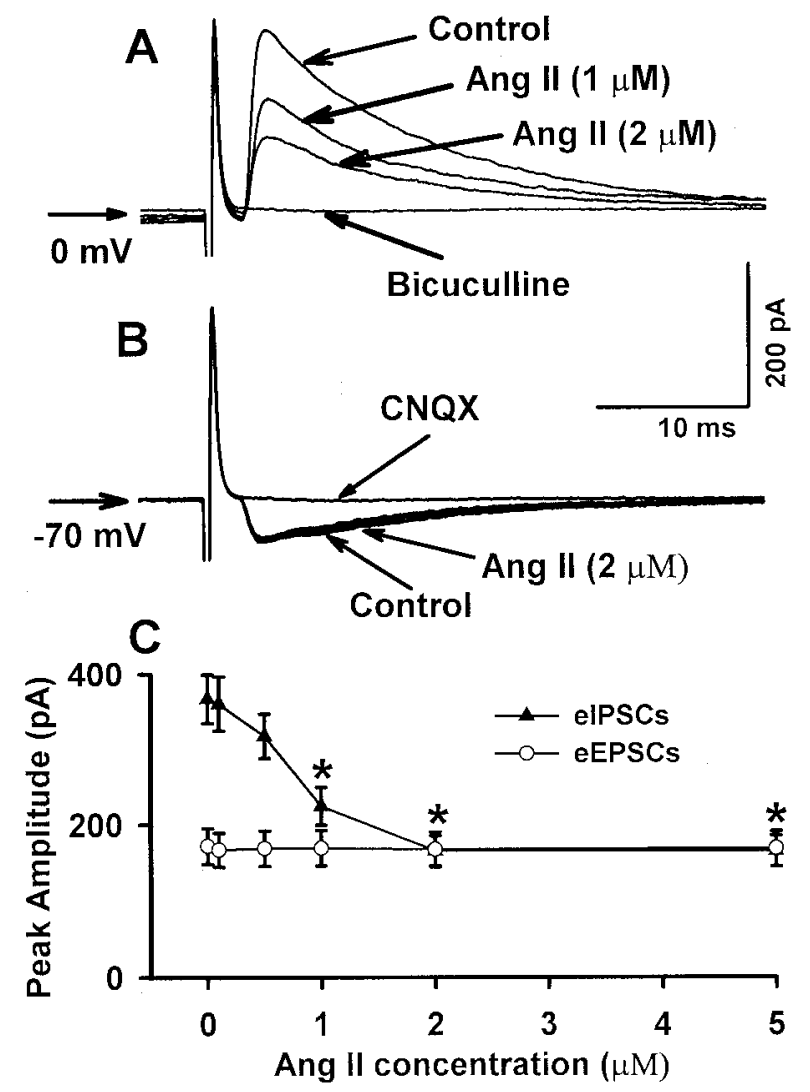

Figure 3. Differential effects of Ang II on evoked IPSCS and EPSCS. A, Original recordings showing that Ang II concentration dependently inhibited eIPSCs. The elPSCs were elicited at a holding potential of $0 \mathrm{mV}$ and abolished by $20 \mu \mathrm{m}$ bicuculline. $B$, Ang II failed to inhibit eEPSCS, which were recorded at a holding potential of $-70 \mathrm{mV}$ and abolished by $20 \mu \mathrm{M}$ CNQX. C, Summary data showing differential effect of $0.5-5 \mu \mathrm{m}$ Ang II on eIPSCS and eEPSCS. Data are presented as means \pm SEM $\left({ }^{*} p<0.05\right.$ compared with control; $n=9$; Kruskal-Wallis ANOVA, followed by Dunn's post hoc test).

previously (Li and Ferguson, 1993, 1996). In nine labeled cells, 2 $\mu \mathrm{M}$ losartan completely blocked the inhibitory effect of $2 \mu \mathrm{M}$ Ang II on the frequency of mIPSCs (Fig. 5C,D). Losartan alone had no effect on mIPSCs of these PVN neurons in the slice preparation (data not shown). However, $2 \mu \mathrm{M}$ PD123319 did not significantly alter the effect of Ang II on the frequency of mIPSCs $(2.88 \pm 0.45$ vs $2.81 \pm 0.43 \mathrm{~Hz}$ ) in another eight cells.

\section{Effect of Ang II on mEPSCs of labeled PVN neurons}

The spontaneous mEPSCs were recorded from FluoSpherelabeled PVN neurons in the presence of $1 \mu \mathrm{M}$ TTX and $20 \mu \mathrm{M}$ bicuculline. Application of $20 \mu \mathrm{M}$ CNQX abolished the mEPSCs $(n=9)$ (Fig. 6A). Neither the frequency nor the amplitude of mEPSCs was affected by bath application of $2 \mu \mathrm{M}$ Ang II $(n=9)$ (Fig. 6). The effect of Ang II on mEPSCs was further analyzed by measuring the time constant of the decay phase of mEPSCs. The decay phase of mEPSCs was best fit by a single-exponential function (Fig. 6D). The decay time constant was similar during control and Ang II application ( $2.58 \pm 0.43$ vs $2.89 \pm 0.38 \mathrm{msec} ; p>$ $0.05 ; n=8)$.

\section{Presynaptic location of $\mathrm{AT}_{1}$ receptors in the PVN}

To determine the presynaptic location of $\mathrm{AT}_{1}$ receptors, doubleimmunofluorescence labeling was performed using specific antibodies against synaptophysin and $\mathrm{AT}_{1}$ receptors in the same brain section. All negative controls (omitting primary antibod- 

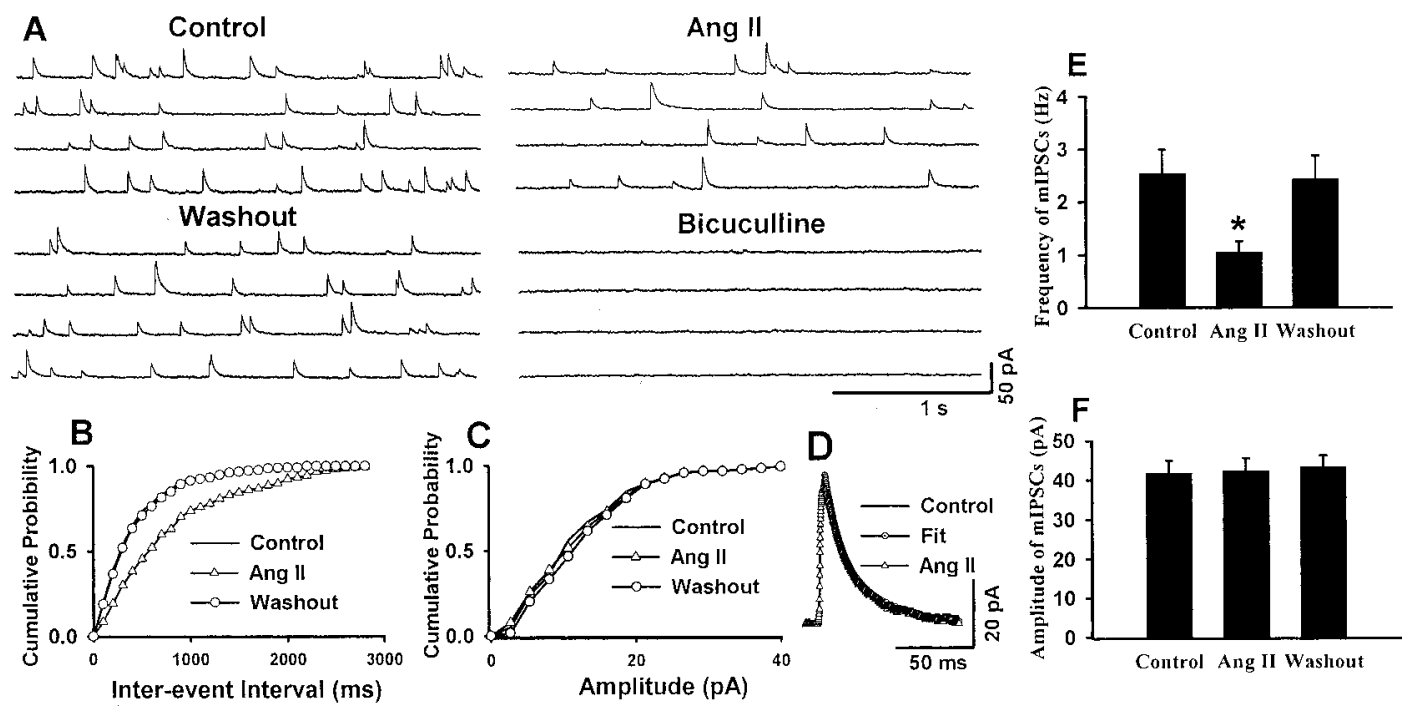

Figure 4. Effect of Ang II on mIPSCs in labeled PVN neurons. A, Representative tracings from a FluoSphere-labeled neuron in the PVN showing mIPSCs recorded during control, application of $2 \mu \mathrm{m}$ Ang II, washout, and application of $20 \mu \mathrm{m}$ bicuculline. Note that bicuculline completely eliminated mIPSCS. B, C, Cumulative probability plot analysis of mIPSCs of the same neuron showing the distribution of the interevent interval $(B)$ and peak amplitude (C) during control, Ang II application, and washout. Ang II increased the interevent interval of mIPSCS ( $p<0.05$; Kolmgorov-Smirnov test) without changing the distribution of the amplitude. D, Superimposed averages of 100 consecutive mIPSCs obtained during control and Ang Il application. The decay phase of mIPSCs was best fitted with a double-exponential function. Both fast $(\tau=5.69 \mathrm{msec})$ and slow $(\tau=16.71 \mathrm{msec})$ components of the decay phase during control and Ang Il administration were similar. E, $F$, Summary data showing the effect of $2 \mu \mathrm{m}$ Ang II on the frequency $(E)$ and amplitude $(F)$ of mIPSCS of nine labeled PVN neurons. Data are presented as means \pm SEM $\left({ }^{*} p<0.05\right.$ compared with the control; Kruskal-Wallis ANOVA, followed by Dunn's post hoc test).
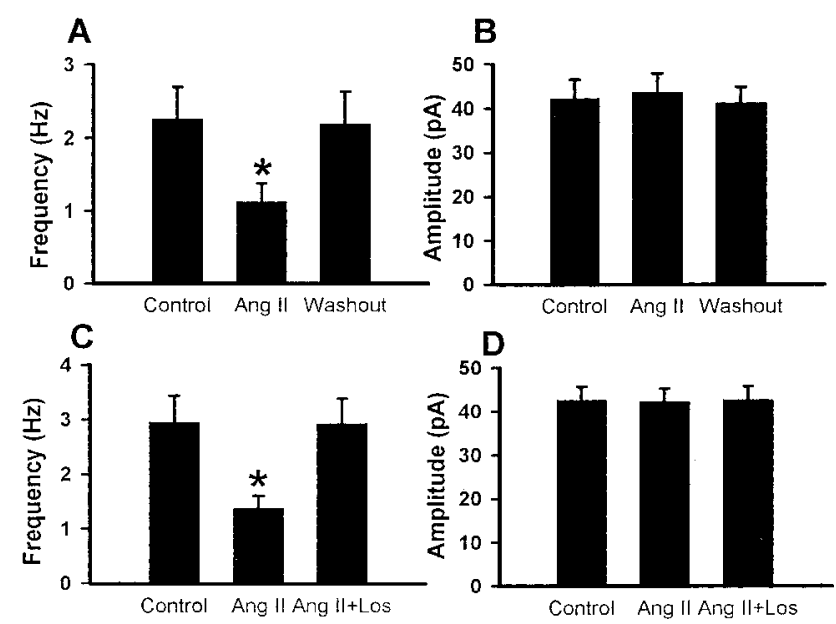

Figure 5. Summary data showing the effect of losartan on the Ang II-induced inhibition on $\mathrm{mIPSCS} . A, B$, The effect of $2 \mu \mathrm{m}$ Ang II on the frequency $(A)$ and amplitude $(B)$ of $\mathrm{mIPSC}$ of nine labeled PVN neurons. GDP- $\beta$-s was included in the recording electrode internal solution. $C, D$, The blockade effect of losartan on Ang II-induced inhibition of mIPSCs. Data are presented as means \pm SEM $\left({ }^{*} p<0.05\right.$ compared with the control; Kruskal-Wallis ANOVA, followed by Dunn's post hoc test). Los, Losartan.

ies) displayed no detectable staining. From the confocal images, numerous puncta immunoreactive for synaptophysin (red) and $\mathrm{AT}_{1}$ receptor (green) were present extensively in the PVN (Fig. 7). The colocalization of synaptophysin- and $\mathrm{AT}_{1}$ receptor immunoreactivity was indicated by the color change (Fig. 7C, yellow) when the synaptophysin and $\mathrm{AT}_{1}$ receptor-stained optical sections were digitally merged. Synaptophysin-positive puncta were colocalized with some but not all $\mathrm{AT}_{1}$ immunoreactivity in the PVN. Also, there were close appositions between $\mathrm{AT}_{1}$ immunoreactive terminals and the soma and dendrites of biocytin-filled neurons (Fig. $7 D-F$ ), suggesting possible synaptic contacts between the $\mathrm{AT}_{1}$ receptor-containing fibers and spinally projecting PVN neurons.

\section{Effect of Ang II and bicuculline on the firing activity of labeled PVN neurons}

Because Ang II preferentially suppressed the inhibitory GABAergic input to labeled PVN neurons, we reasoned that the excitability of these neurons would be increased by Ang II. To directly test this hypothesis, the effect of $2 \mu \mathrm{M}$ Ang II on the spontaneous firing activity of labeled PVN neurons was determined using whole-cell current-clamp recordings. The majority of the labeled PVN neurons recorded displayed spontaneous activity (32 of 41; $78 \%$ ). In eight PVN neurons tested, $2 \mu \mathrm{M}$ Ang II significantly increased the discharge rate from $3.83 \pm 0.49$ to $6.81 \pm 0.77 \mathrm{~Hz}$ $(p<0.05)$. The membrane potential was not significantly altered by Ang II $(-70.3 \pm 1.47$ to $-67.8 \pm 1.49 \mathrm{mV} ; n=8 ; p>0.05)$. The excitatory effect of $2 \mu \mathrm{M}$ Ang II on the firing activity of labeled PVN neurons was reproducible (Fig. $8 A$ ). Losartan and PD123319 were used to determine the receptor subtype mediating the Ang II-induced excitation of PVN neurons. In another eight labeled PVN neurons, $2 \mu \mathrm{M}$ losartan completely blocked the excitatory effect of Ang II on these cells (Fig. 8B,C). However, Ang II-induced excitation of PVN neurons was not altered significantly by $2 \mu \mathrm{M}$ PD123319 in another group of seven neurons. In seven additional PVN neurons, GDP- $\beta$-s was included in the pipette internal solution to block the possible postsynaptic effect of Ang II. Perfusion of $2 \mu \mathrm{M}$ Ang II still increased the firing rate of these cells from $3.36 \pm 0.63$ to $6.56 \pm 0.85 \mathrm{~Hz}(n=7 ; p<0.05)$.

To determine the role of GABAergic synaptic inputs in the excitatory effect of Ang II on labeled PVN neurons, the effect of Ang II on the firing activity of PVN neurons was tested in the presence of the $\mathrm{GABA}_{\mathrm{A}}$ receptor antagonist bicuculline. The spontaneous activity of nine labeled PVN neurons was significantly increased after the perfusion of $20 \mu \mathrm{M}$ bicuculline (Fig. 9). However, subsequent application of $2 \mu \mathrm{M}$ Ang II failed to further 
A
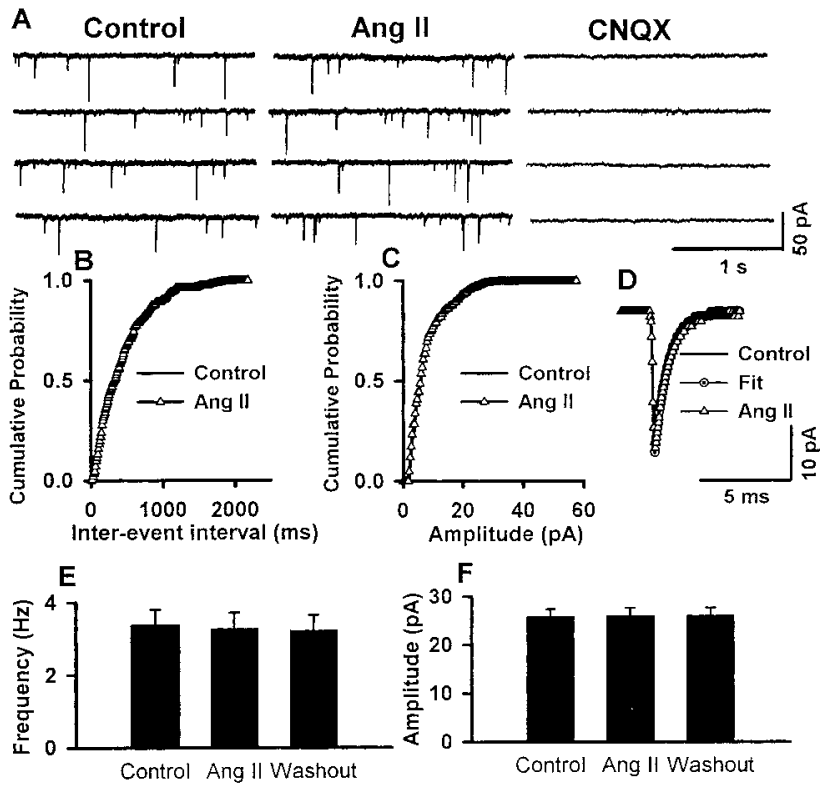

Figure 6. Lack of effect of Ang II on mEPSCs in labeled PVN neurons. $A$, Representative tracings from a labeled neuron in the PVN showing spontaneous mEPSCs during control, application of $2 \mu \mathrm{m}$ Ang II, and application of $20 \mu \mathrm{m}$ CNQX. B, C, Cumulative plot analysis of mEPSCS of the same neuron showing the distribution of the interevent interval $(B)$ and amplitude $(C)$ during control and application of $2 \mu \mathrm{m}$ Ang II. Neither the interevent interval nor the amplitude of $\mathrm{mEPSC}$ was affected by Ang II. D, Superimposed averages of 100 consecutive mEPSCs obtained during control and Ang II application. The decay phase of mEPSC $s$ was best fitted with a single-exponential function. The decay time constant was similar during control ( $\tau=2.87$ msec) and Ang II application ( $\tau=2.74 \mathrm{msec}$ ). E, F, Summary data showing the effect of $2 \mu \mathrm{m}$ Ang $I I$ on the frequency $(E)$ and amplitude $(F)$ of mEPSCs in nine labeled PVN neurons. Data are presented as means \pm SEM.

increase the firing activity of these nine PVN neurons in the presence of $20 \mu \mathrm{M}$ bicuculline (Fig. 9A-C).

\section{Discussion}

This is the first electrophysiological study to examine the synaptic mechanisms of the excitatory effect of Ang II on spinally projecting PVN neurons. We found that Ang II significantly inhibited the evoked GABAergic IPSCs in a concentration-dependent manner. Also, Ang II decreased the frequency of GABAergic mIPSCs without affecting the amplitude and the decay time constant of mIPSCs. Ang II-induced suppression of mIPSCs was completely abolished by losartan but not PD123319. On the other hand, Ang II had no effect on glutamatergic mEPSCs or eEPSCs of labeled PVN neurons at concentrations that attenuated GABAergic IPSCs. Furthermore, we observed that Ang II significantly increased the discharge activity of PVN neurons, and this excitatory effect was eliminated in the presence of bicuculline, a $\mathrm{GABA}_{\mathrm{A}}$ receptor antagonist. Therefore, the present study provides substantial new evidence that Ang II increases the excitability of spinally projecting PVN neurons by attenuation of the inhibitory GABAergic synaptic input, an effect that is likely mediated by activation of presynaptic $\mathrm{AT}_{1}$ receptors.

The PVN is composed of two general populations of neurons: the magnocellular neurons, which project to the posterior pituitary, and the parvocellular neurons, which project to the anterior pituitary and other areas of the brain and spinal cord (Swanson and Sawchenko, 1983; Boudaba et al., 1996; Shafton et al., 1998; Hardy, 2001). The physiological study of synaptic inputs to the PVN is complicated by the heterogeneity of cell types in the nucleus. It has been shown that the electrophysiological properties
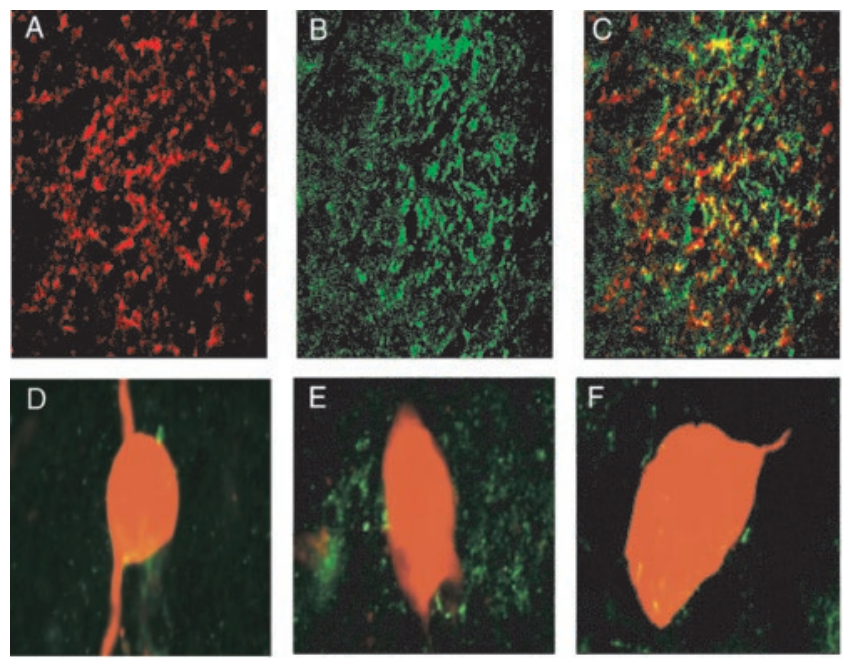

Figure 7. Confocal images showing the colocolization of synaptophysin and $A T_{1}$ receptor immunoreactivities in the PVN. $A, B$, Synaptophysin $\left(A\right.$, red) and $A T_{1}$ receptor ( $B$, green) immunoreactivities in the PVN viewed under a confocal microscope. $C$, Digitally merged images from $A$ and $B$. Note that the synaptophysin and $\mathrm{AT}_{1}$ receptor immunoreactivities are colocalized in the PVN (yellow). Magnification: $A-C, 800 \times . D-F$, Higher-magnification confocal images showing that $\mathrm{AT}_{1}$-containing varicosities (green) are in close apposition to the soma or dendrites of three biocytin-filled (red) cells. Magnification: $D-F, 5040 \times$. All images are single confocal optical sections.

of spinally projecting PVN neurons, such as low input resistance, are distinctively different from other neurons in the PVN (Cui et al., 2001). In the present study, we used the retrograde-labeling technique to identify the PVN neurons projecting to the spinal cord to specifically study this descending pathway related to the control of sympathetic drive. The approach used in this study has important advantages for studying heterogenous neurons with spinal projections, because retrogradely labeled PVN neurons can be visualized in defined cytoarchitectonic regions in vitro. GABAergic and glutamatergic synaptic inputs are considered to be the two major inhibitory and excitatory synaptic inputs to the PVN neurons (Decavel and Van den Pol, 1990; Hermes et al., 1996; Cui et al., 2001). Because both evoked and miniature IPSCs of labeled PVN neurons were eliminated by the $\mathrm{GABA}_{\mathrm{A}}$ receptor antagonist bicuculline, the IPSCs represent synaptic GABA release from the presynaptic terminals. In contrast, both evoked and miniature EPSCs were completely abolished by CNQX, suggesting that the EPSCs reflect the release of glutamate from the presynaptic terminals (Hermes et al., 1996). Therefore, spinally projecting PVN neurons are under dual modulation of inhibitory GABAergic and excitatory glutamatergic inputs (Li et al., 2002a).

The most salient finding of this study is that Ang II has a preferential inhibitory effect on GABAergic synaptic inputs to spinally projecting PVN neurons. In this regard, we found that Ang II decreased the amplitude of GABAergic eIPSCs and the frequency of GABAergic mIPSCs in labeled PVN neurons, regardless of the blockade of a possible postsynaptic effect of Ang II with GDP- $\beta$-s included in the pipette internal solution (Ohya and Sperelakis, 1991; Oz and Renaud, 2002). This observation suggests that Ang II decreases the synaptic GABA release, and the likely site of its action is at the presynaptic GABAergic terminals. Furthermore, we found that Ang II had a similar excitatory effect on the firing activity of labeled PVN neurons in the presence and absence of GDP- $\beta$-s. The immunocytochemistry experiments provide additional complementary evidence that $\mathrm{AT}_{1}$ receptors are located at least in part at the presynaptic terminals in a close apposition to spinally projecting PVN neurons. Therefore, these 

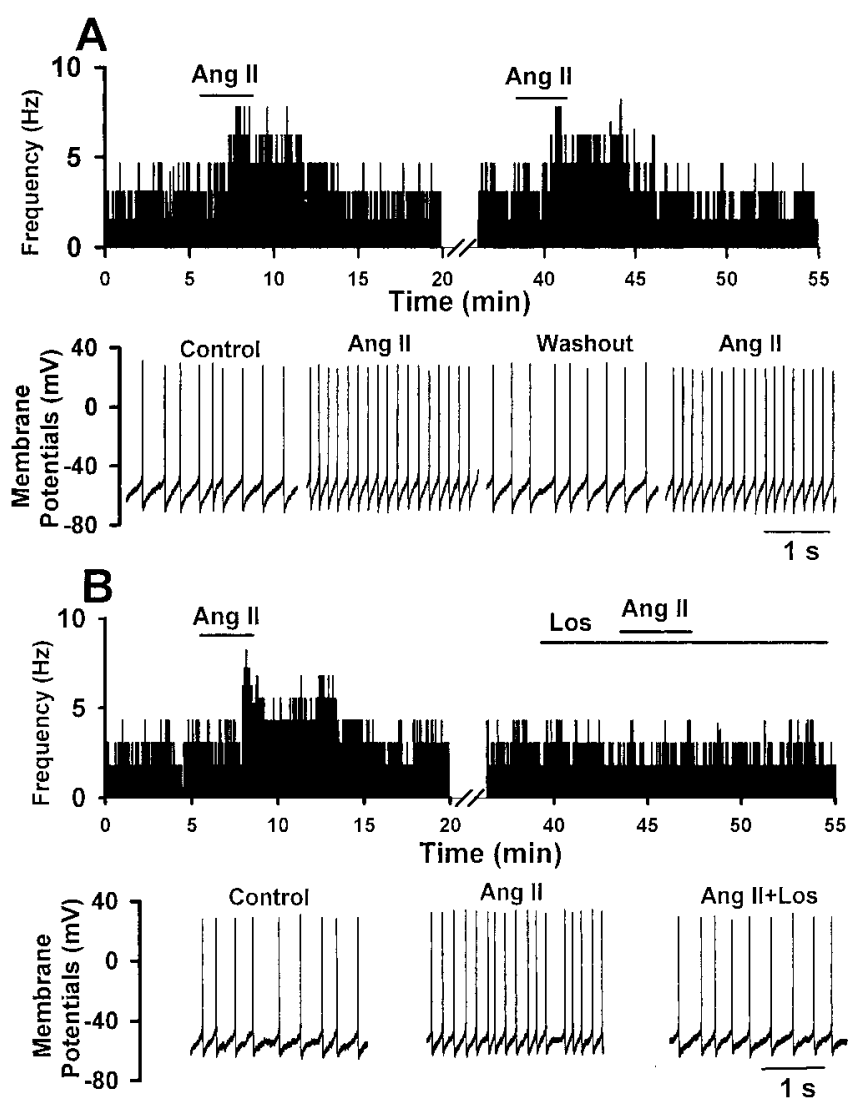

Ang 11
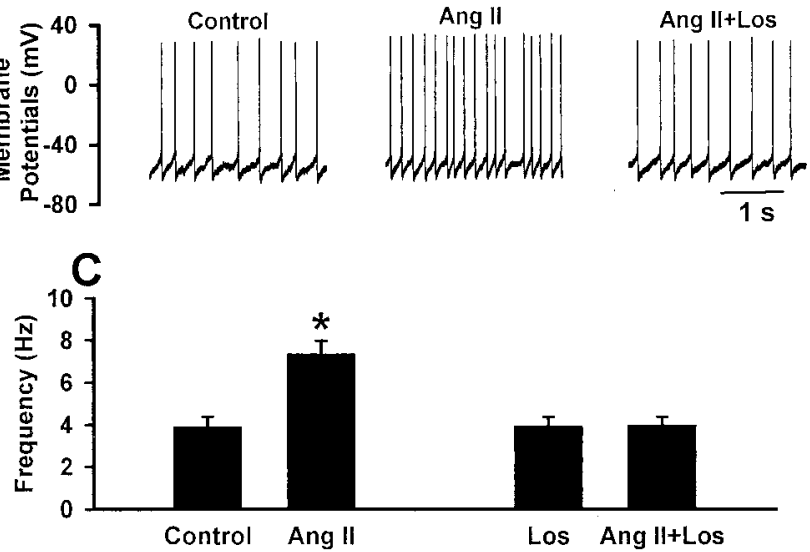

Figure 8. Excitatory effect of Ang Il and losartan on the firing activity of labeled PVN neurons. A, Top, Histogram showing the reproducible effect of $2 \mu \mathrm{m}$ Ang II on the firing activity of a labeled PVN neuron. Bottom, Raw tracings showing the spontaneous activity of the same cell during control, application of Ang II, and washout. Note that Ang II increased the discharge activity of the neuron in a reproducible manner. $B$, Top, Histogram showing the effect of losartan on the Ang Il-induced excitation of a PVN neuron. Bottom, Raw tracings showing the spontaneous activity of the same cell during control, application of $2 \mu \mathrm{m} \mathrm{Ang} \mathrm{II,} \mathrm{and} 2 \mu \mathrm{m}$ Ang II plus $2 \mu \mathrm{m}$ losartan. C, Effects of $2 \mu \mathrm{m}$ Ang $\|$ and $2 \mu \mathrm{m}$ Ang $\|$ plus $2 \mu \mathrm{m}$ losartan on the firing activity of eight FluoSphere-labeled PVN neurons. Note that losartan completely eliminated the effect of Ang II. Data are presented as means \pm SEM $\left({ }^{*} p<0.05\right.$ compared with control; KruskalWallis ANOVA, followed by Dunn's post hoc test). Los, Losartan.

data provide strong evidence that the Ang II site of action on the spinally projecting PVN neurons is at the presynaptic terminals. This finding is consistent with a previous study showing the presynaptic location of $\mathrm{AT}_{1}$ receptors in other brain sites such as the nucleus of the solitary tract (Qu et al., 1996). Although Ang II elicits a small membrane depolarization in the PVN magnocellular neurons by inhibition of a potassium current (Li and Ferguson, 1996), there are no available data showing that Ang II has a postsynaptic effect on spinally projecting parvocellular PVN neurons. We acknowledge that, although Ang II had no evident postsynaptic effect on the synaptic transmission and firing activity in spinally projecting PVN neurons through a postsynaptic action, we cannot completely rule out the possibility that Ang II
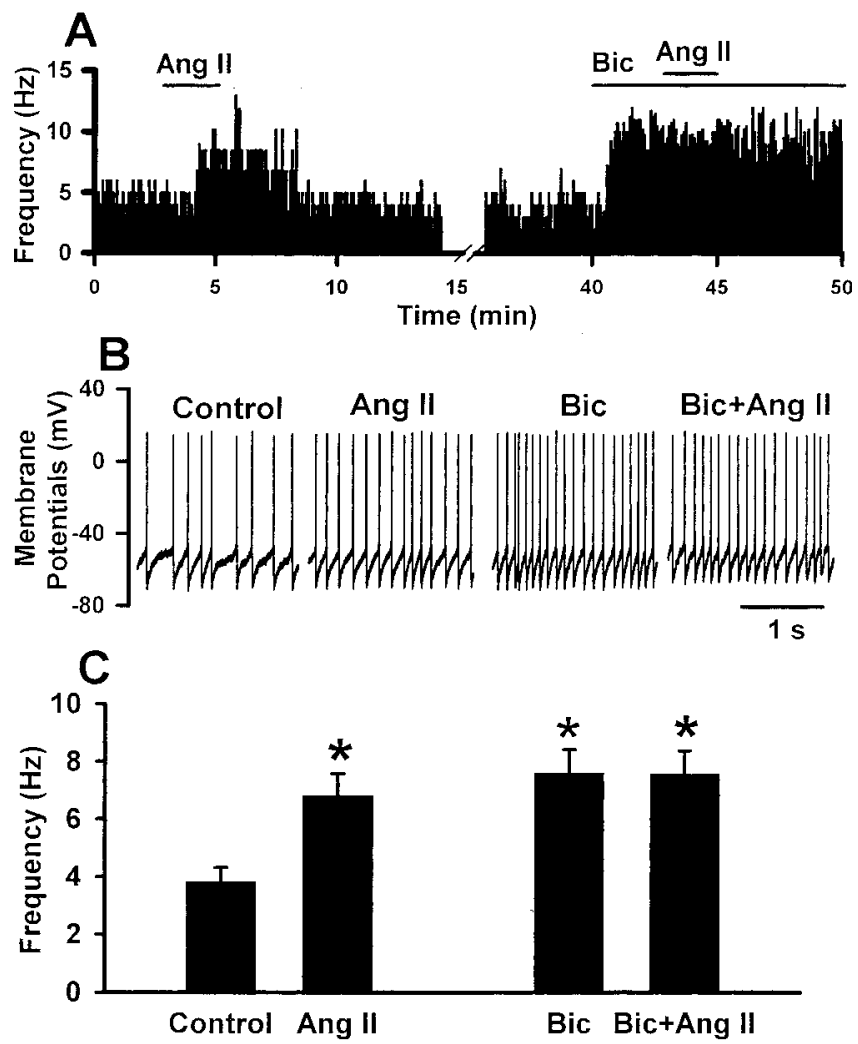

Figure 9. Effects of Ang ll and bicuculline on the discharge activity of labeled PVN neurons. $A$, Histogram showing the effect of $2 \mu \mathrm{m}$ Ang II, $20 \mu \mathrm{m}$ bicuculline, and $2 \mu \mathrm{m}$ Ang II plus $20 \mu \mathrm{m}$ bicuculline on the firing activity of a labeled PVN neuron. $B$, Original tracings recorded during control, application of Ang II, bicuculline alone, and Ang II plus bicuculline from the same neuron shown in $A$. Note that Ang $I I$ failed to increase the firing activity of this neuron in the presence of bicuculline. C, Effect of $2 \mu \mathrm{m}$ Ang $I I$ and $2 \mu \mathrm{m}$ Ang $I I$ plus $20 \mu \mathrm{m}$ bicuculline on the firing activity of another group of nine labeled PVN neurons. Data are presented as means \pm SEM ( ${ }^{*} p<0.05$ compared with control; Kruskal-Wallis ANOVA, followed by Dunn's post hoc test). Bic, Bicuculline.

may have other postsynaptic effects that are not detected using this slice preparation. In contrast to its action on GABAergic eIPSCs and mIPSCs, Ang II had no significant effect on the glutamatergic eEPSCs and mEPSCs in labeled PVN neurons. The reasons for the selective effect of Ang II on GABAergic IPSCs are unclear. It may be caused by lack of sufficient functional $\mathrm{AT}_{1}$ receptors on the glutamatergic nerve terminals in the PVN.

We found that both Ang II-induced inhibition of mIPSCs and excitation of labeled PVN neurons were completely blocked by the specific $\mathrm{AT}_{1}$ receptor antagonist losartan. This finding is consistent with previous studies showing that $\mathrm{AT}_{1}$ receptors and their mRNA are expressed in the PVN, although the precise cellular location (projection neurons, interneurons, or presynaptic terminals) of $\mathrm{AT}_{1}$ receptors were not determined (Obermuller et al., 1991; Aguilera et al., 1995). In contrast, the $\mathrm{AT}_{2}$ receptors in the brain are predominately located in the pons (Rowe et al., 1991; Song et al., 1992). Although the $\mathrm{AT}_{2}$ receptor immunoreactivity in the PVN has been reported, the receptor autoradiographic studies have failed to find the binding sites for $\mathrm{AT}_{2}$ receptors in the PVN (Gehlert et al., 1991; Song et al., 1992). We found that the specific $\mathrm{AT}_{2}$ antagonist PD123319 did not alter the effect of Ang II on mIPSCs and the firing activity of labeled PVN neurons. Therefore, our data suggest that $\mathrm{AT}_{1}$, but not $\mathrm{AT}_{2}$, receptors are involved in the presynaptic effect of Ang II on spinally projecting PVN neurons. 
On the basis of the observation that Ang II preferentially attenuated the inhibitory GABAergic synaptic input to labeled PVN neurons without an evident effect on the glutamatergic synaptic input, we hypothesized that Ang II increases the excitability of PVN neurons through suppression of inhibitory GABAergic inputs (disinhibition). In the present study, bicuculline alone produced a significant increase in the firing activity in all the cells examined, indicating the presence of a tonic inhibition by the GABAergic synaptic input to spinally projecting PVN neurons (Li et al., 2002a). We also found that Ang II consistently increased the excitability of these spinally projecting PVN neurons. Importantly, Ang II failed to increase the firing activity of PVN neurons in the presence of bicuculline. Thus, these data provide compelling evidence that suppression of the GABAergic inhibitory input is ultimately involved in the excitatory effect of Ang II on spinally projecting PVN neurons.

The renin-angiotensin system is upregulated in the PVN during disease conditions such as heart failure, stress, and hypertension (Harding et al., 1992; Qadri et al., 1994; Li et al., 1996; Dumont et al., 1999). Furthermore, the blood-borne Ang II is elevated in these pathophysiological conditions, and the circulating Ang II can increase the excitability of PVN neurons connecting to circumventricular organs (Harding et al., 1992; Dumont et al., 1999; Miyakubo et al., 2002; Zhang et al., 2002). By attenuation of GABAergic synaptic inputs to spinally projecting PVN neurons, Ang II can excite these cells to augment and maintain the high level of sympathetic outflow during stress, heart failure, and hypertension. There is no information available regarding the actual concentration of Ang II in the PVN in vivo. The plasma concentration of Ang II measured by radioimmunoassay has been reported to be $\sim 240 \mathrm{pg} / \mathrm{ml}(0.24 \mathrm{~nm})$ in hypertension and $150 \mathrm{pg} / \mathrm{ml}$ (0.15 nM) in heart failure (Luchner et al., 1996; Morato et al., 2002). Although the concentration of Ang II used in this in vitro study appeared to be higher than that in the blood level, it is possible that PVN neurons could be exposed to locally produced Ang II within the PVN in addition to the blood-borne Ang II (Harding et al., 1992; Li and Ferguson, 1993; Ferguson and Washburn, 1998).

In summary, this study provides novel information about the synaptic mechanisms through which Ang II activates spinally projecting PVN neurons. Ang II significantly attenuated GABAergic, but not the glutamatergic, synaptic inputs to PVN neurons through activation of presynaptic $\mathrm{AT}_{1}$ receptors. Furthermore, Ang II increased the excitability of spinally projecting PVN neurons, and such an effect was eliminated in the presence of bicuculline. Collectively, data from this integrative study provide substantial functional evidence that Ang II potentiates the excitability of spinally projecting PVN neurons through attenuation of GABAergic synaptic inputs. This new information is important for understanding the mechanisms of regulation of PVN autonomic neurons by Ang II during physiological and pathological conditions.

\section{References}

Aguilera G, Kiss A, Luo X (1995) Increased expression of type 1 angiotensin II receptors in the hypothalamic paraventricular nucleus following stress and glucocorticoid administration. J Neuroendocrinol 7:775-783.

Allen AM (2002) Inhibition of the hypothalamic paraventricular nucleus in spontaneously hypertensive rats dramatically reduces sympathetic vasomotor tone. Hypertension 39:275-280.

Bains JS, Ferguson AV (1995) Paraventricular nucleus neurons projecting to the spinal cord receive excitatory input from the subfornical organ. Am J Physiol 268:R625-R633.

Boudaba C, Szabo K, Tasker JG (1996) Physiological mapping of local in- hibitory inputs to the hypothalamic paraventricular nucleus. J Neurosci 16:7151-7160.

Chen QH, Toney GM (2001) AT(1)-receptor blockade in the hypothalamic PVN reduces central hyperosmolality-induced renal sympathoexcitation. Am J Physiol Regul Integr Comp Physiol 281:R1844-R1853.

Cui LN, Coderre E, Renaud LP (2001) Glutamate and GABA mediate suprachiasmatic nucleus inputs to spinal-projecting paraventricular neurons. Am J Physiol Regul Integr Comp Physiol 281:R1283-R1289.

Decavel C, Van den Pol AN (1990) GABA: a dominant neurotransmitter in the hypothalamus. J Comp Neurol 302:1019-1037.

de Wardener HE (2001) The hypothalamus and hypertension. Physiol Rev 81:1599-1658.

Dumont EC, Rafrafi S, Laforest S, Drolet G (1999) Involvement of central angiotensin receptors in stress adaptation. Neuroscience 93:877-884.

Ferguson AV, Washburn DL (1998) Angiotensin II: a peptidergic neurotransmitter in central autonomic pathways. Prog Neurobiol 54:169-192.

Gehlert DR, Gackenheimer SL, Schober DA (1991) Autoradiographic localization of subtypes of angiotensin II antagonist binding in the rat brain. Neuroscience 44:501-514.

Harding JW, Jensen LL, Hanesworth JM, Roberts KA, Page TA, Wright JW (1992) Release of angiotensins in paraventricular nucleus of rat in response to physiological and chemical stimuli. Am J Physiol 262:F17-F23.

Hardy SG (2001) Hypothalamic projections to cardiovascular centers of the medulla. Brain Res 894:233-240.

Hermes ML, Coderre EM, Buijs RM, Renaud LP (1996) GABA and glutamate mediate rapid neurotransmission from suprachiasmatic nucleus to hypothalamic paraventricular nucleus in rat. J Physiol (Lond) 496:749-757.

Hiscock JJ, Murphy S, Willoughby JO (2000) Confocal microscopic estimation of GABAergic nerve terminals in the central nervous system. J Neurosci Methods 95:1-11.

Hogarty DC, Speakman EA, Puig V, Phillips MI (1992) The role of angiotensin, AT1 and AT2 receptors in the pressor, drinking and vasopressin responses to central angiotensin. Brain Res 586:289-294.

Li DP, Pan HL (2001) Potentiation of glutamatergic synaptic input to supraoptic neurons by presynaptic nicotinic receptors. Am J Physiol Regul Integr Comp Physiol 281:R1105-R1113.

Li DP, Chen SR, Pan HL (2002a) Nitric oxide inhibits spinally projecting paraventricular neurons through potentiation of presynaptic GABA release. J Neurophysiol 88:2664-2674.

Li DP, Chen SR, Pan YZ, Levey AI, Pan HL (2002b) Role of presynaptic muscarinic and GABAB receptors in synaptic glutamate release onto lamina II neurons in rats. J Physiol (Lond) 543:807-818.

Li P, Morris M, Diz DI, Ferrario CM, Ganten D, Callahan MF (1996) Role of paraventricular angiotensin AT1 receptors in salt-sensitive hypertension in mRen-2 transgenic rats. Am J Physiol 270:R1178-R1181.

LiZ, Ferguson AV (1993) Angiotensin II responsiveness of rat paraventricular and subfornical organ neurons in vitro. Neuroscience 55:197-207.

LiZ, Ferguson AV (1996) Electrophysiological properties of paraventricular magnocellular neurons in rat brain slices: modulation of IA by angiotensin II. Neuroscience 71:133-145.

Lind RW, Swanson LW, Bruhn TO, Ganten D (1985) The distribution of angiotensin II-immunoreactive cells and fibers in the paraventriculohypophysial system of the rat. Brain Res 338:81-89.

Lon S, Szczepanska-Sadowska E, Szczypaczewska M (1996) Evidence that centrally released arginine vasopressin is involved in central pressor action of angiotensin II. Am J Physiol 270:H167-H173.

Luchner A, Stevens TL, Borgeson DD, Redfield MM, Bailey JE, Sandberg SM, Heublein DM, Burnett Jr JC (1996) Angiotensin II in the evolution of experimental heart failure. Hypertension 28:472-477.

Martin DS, Haywood JR (1993) Hemodynamic responses to paraventricular nucleus disinhibition with bicuculline in conscious rats. Am J Physiol 265:H1727-H1733.

Miyakubo H, Hayashi Y, Tanaka J (2002) Enhanced response of subfornical organ neurons projecting to the hypothalamic paraventricular nucleus to angiotensin II in spontaneously hypertensive rats. Auton Neurosci 95:131-136.

Morato M, Sousa T, Guimaraes S, Moura D, Albino-Teixeira A (2002) The role of angiotensin II in hypertension due to adenosine receptors blockade. Eur J Pharmacol 455:135-141.

Obermuller N, Unger T, Culman J, Gohlke P, de Gasparo M, Bottari SP 
(1991) Distribution of angiotensin II receptor subtypes in rat brain nuclei. Neurosci Lett 132:11-15.

Ohya Y, Sperelakis N (1991) Involvement of a GTP-binding protein in stimulating action of angiotensin II on calcium channels in vascular smooth muscle cells. Circ Res 68:763-771.

Oz M, Renaud LP (2002) Angiotensin AT(1)-receptors depolarize neonatal spinal motoneurons and other ventral horn neurons via two different conductances. J Neurophysiol 88:2857-2863.

Pan YZ, Li DP, Chen SR, Pan HL (2002) Activation of delta-opioid receptors excites spinally projecting locus coeruleus neurons through inhibition of GABAergic inputs. J Neurophysiol 88:2675-2683.

Pyner S, Coote JH (2000) Identification of branching paraventricular neurons of the hypothalamus that project to the rostroventrolateral medulla and spinal cord. Neuroscience 100:549-556.

Qadri F, Edling O, Wolf A, Gohlke P, Culman J, Unger T (1994) Release of angiotensin in the paraventricular nucleus in response to hyperosmotic stimulation in conscious rats: a microdialysis study. Brain Res 637:45-49.

Qu L, McQueeney AJ, Barnes KL (1996) Presynaptic or postsynaptic location of receptors for angiotensin II and substance P in the medial solitary tract nucleus. J Neurophysiol 75:2220-2228.

Ranson RN, Motawei K, Pyner S, Coote JH (1998) The paraventricular nucleus of the hypothalamus sends efferents to the spinal cord of the rat that closely appose sympathetic preganglionic neurones projecting to the stellate ganglion. Exp Brain Res 120:164-172.
Rowe BP, Grove KL, Saylor DL, Speth RC (1991) Discrimination of angiotensin II receptor subtype distribution in the rat brain using non-peptidic receptor antagonists. Regul Pept 33:45-53.

Schlenker E, Barnes L, Hansen S, Martin D (2001) Cardiorespiratory and metabolic responses to injection of bicuculline into the hypothalamic paraventricular nucleus (PVN) of conscious rats. Brain Res 895:33-40.

Shafton AD, Ryan A, Badoer E (1998) Neurons in the hypothalamic paraventricular nucleus send collaterals to the spinal cord and to the rostral ventrolateral medulla in the rat. Brain Res 801:239-243.

Song K, Allen AM, Paxinos G, Mendelsohn FA (1992) Mapping of angiotensin II receptor subtype heterogeneity in rat brain. J Comp Neurol 316:467-484

Swanson LW, Sawchenko PE (1983) Hypothalamic integration: organization of the paraventricular and supraoptic nuclei. Annu Rev Neurosci 6:269-324.

Tasker JG, Dudek FE (1993) Local inhibitory synaptic inputs to neurones of the paraventricular nucleus in slices of rat hypothalamus. J Physiol (Lond) 469:179-192.

Zhang ZH, Francis J, Weiss RM, Felder RB (2002) The renin-angiotensinaldosterone system excites hypothalamic paraventricular nucleus neurons in heart failure. Am J Physiol Heart Circ Physiol 283:H423-H433.

Zhu GQ, Patel KP, Zucker IH, Wang W (2002) Microinjection of ANG II into paraventricular nucleus enhances cardiac sympathetic afferent reflex in rats. Am J Physiol Heart Circ Physiol 282:H2039-H2045. 